\title{
Lovastatin Inhibits Proliferation of Rat Mesangial Cells
}

Michael P. O'Donnell, Bertram L. Kasiske, Youngki Kim, Durgaprasadarao Atluru, and William F. Keane

Division of Nephrology, Department of Medicine, Hennepin County Medical Center; and Department of Pediatrics, University of Minnesota, Minneapolis, Minnesota 55415

\begin{abstract}
Products of intracellular mevalonate metabolism are essential for cell growth and proliferation. Lovastatin, an inhibitor of 3-hydroxy-3-methylglutaryl coenzyme A reductase, blocks the formation of mevalonate and its metabolites, and has been shown to inhibit proliferation of several cell types. In vivo, lovastatin has reduced mesangial cellularity and glomerular injury in experimental renal disease. In this study, we investigated the effects of lovastatin on DNA replication and proliferation in rat glomerular mesangial cells. Growth-arrested mesangial cells were exposed to medium containing $10 \%$ fetal bovine serum to stimulate mitogenesis. Lovastatin (1-20 $\mu \mathrm{M})$ caused a significant $(P<0.05)$ dose-dependent reduction in DNA synthesis $\left({ }^{3} \mathrm{H}\right]$ thymidine incorporation) which was completely prevented in the presence of exogenous mevalonate $(100$ $\mu \mathrm{M})$. Lovastatin $(1 \mu \mathrm{M})$ inhibited cell proliferation by $90 \%$ over a 5-d period, and this was largely overcome by added mevalonate. Exogenous low density lipoprotein $(100 \mu \mathrm{g} / \mathrm{ml})$ did not prevent lovastatin inhibition of DNA synthesis. The isoprenoid end product isopentenyl adenine ( 5 or $50 \mu \mathrm{M})$ had little effect on DNA synthesis and cell proliferation in lovastatinblocked cells. By contrast, the isoprenoid farnesol $(5 \mu \mathrm{M})$ largely prevented lovastatin inhibition of DNA synthesis. We conclude that mevalonate metabolism is essential for mesangial cell proliferation, possibly through the production of the isoprenoid farnesol. Moreover, the action of lovastatin to reduce experimental glomerular injury may involve a direct effect on mesangial cells. (J. Clin. Invest. 1993. 91:83-87.) Key words: mevalonate $\bullet$ isoprenoids $\bullet$ farnesol $\bullet$ glomerulus $\bullet$ glomerulosclerosis
\end{abstract}

\section{Introduction}

Products of the mevalonate pathway play a critical role in DNA replication and cell proliferation (1-8). Mevalonate is synthesized intracellularly from 3-hydroxy-3-methylglutaryl coenzyme A (HMG-CoA) ${ }^{1}$ and this process is catalyzed by the enzyme HMG-CoA reductase. Mevalonate metabolism yields a series of isoprenoid compounds which are incorporated into

Address correspondence to Michael P. O'Donnell, Ph.D., Regional Kidney Disease Program, Hennepin County Medical Center, 914 S. Eighth Street, Minneapolis, MN 55404.

Received for publication 18 March 1992 and in revised form 27 July 1992.

1. Abbreviations used in this paper: HMG-CoA, 3-hydroxy-3-methylglutaryl coenzyme A; IPA, isopentenyl adenine.

J. Clin. Invest.

(c) The American Society for Clinical Investigation, Inc. $0021-9738 / 93 / 01 / 83 / 05 \quad \$ 2.00$

Volume 91, January 1993, 83-87 cholesterol, isopentenyl adenine, farnesylated proteins, and other end products essential for cell growth $(3,5,8)$. Inhibition of HMG-CoA reductase with agents such as compactin or lovastatin blocks the production of mevalonate and has been shown to inhibit DNA synthesis and proliferation in several cell types (1-8).

Many glomerular diseases are characterized by mesangial cell proliferation and accumulation of mesangial extracellular matrix. Indeed, these processes precede, and possibly cause, the development of glomerulosclerosis. We previously found in several experimental models of progressive glomerular disease that treatment with lovastatin reduced mesangial cellularity and extracellular matrix expansion. These effects of lovastatin were seen in obese Zucker rats, Dahl salt-sensitive rats, and rats with subtotal renal ablation (9-11). Because lovastatin also reduced serum lipids in these experimental models, we attributed the beneficial effects of lovastatin, at least in part, to the lowering of circulating lipids (9-11). Given the evidence that lovastatin can inhibit cell growth, however, it is conceivable that lovastatin may also have affected mesangial cell proliferation in our experimental models of glomerular disease.

This study was designed to investigate this possibility. Mesangial cells were isolated from glomeruli of young obese Zucker rats, subcultured, and the effects of lovastatin on DNA synthesis and cell proliferation were determined. We chose to study mesangial cells of obese Zucker rats because previous experiments demonstrated a significant action of lovastatin in vivo to reduce mesangial cellularity and matrix expansion in this experimental model of glomerular disease.

\section{Methods}

Reagents. RPMI 1640, insulin-transferrin-selenite media supplement, mevalonic acid lactone, $N^{6}$-[isopentenyl]adenine, and farnesol were obtained from Sigma Chemical Co., St. Louis, MO. Trypsin-EDTA and collagenase were from Gibco Laboratories, Grand Island, NY. Fetal bovine serum was supplied by Bioproducts for Science, Inc., Indianapolis, IN. Lovastatin was graciously provided by Merck Sharp and Dohme, Inc., West Point, PA.

Mevalonic acid lactone $(32.5 \mathrm{mg}$ ) was solubilized in $2 \mathrm{ml}$ absolute ethanol and added to $23 \mathrm{ml}$ RPMI 1640, $\mathrm{pH} 7.40$, to produce the mevalonate salt. Isopentenyl adenine was solubilized and stored in 0.1 $\mathrm{N} \mathrm{NaOH}$. Lovastatin salt was prepared as described by Kita et al. (12). Aliquots of the above solutions were stored at $-20^{\circ} \mathrm{C}$.

Mesangial cell culture. Rat mesangial cells were isolated and grown in culture using procedures previously described by others (13-15) and adapted for use in our laboratory. Glomeruli from 6-wk old obese Zucker rats were obtained by sequential sieving of renal cortical tissue through stainless steel screens. Tissue isolated on a 325-mesh screen contained $>90 \%$ glomeruli. The glomerular fraction was treated with trypsin-EDTA and collagenase $(1 \mathrm{mg} / \mathrm{ml})$, washed several times, and seeded in 24-well culture plates. The culture medium consisted of RPMI 1640 containing $15 \mathrm{mM}$ Hepes, $5 \mathrm{ml}$ insulin-transferrin-selenite per liter, $10 \%$ heat-inactivated fetal bovine serum, penicillin $(100,000$ $\mathrm{U} /$ liter $)$, and streptomycin $(100 \mathrm{mg} / \mathrm{liter})$. From the manufacturer's 
assay of the fetal bovine serum, the cholesterol concentration of the serum-supplemented medium was calculated to be $\sim 40 \mu \mathrm{g} / \mathrm{ml}$.

Mesangial cell outgrowth from the glomerular fragments was observed after several days, and was allowed to proceed for $2 \mathrm{wk}$. Cells were then passaged, placed again in 24-well plates, and allowed to reach confluency. Subcultures were thereafter prepared every 7-10 d in 75$\mathrm{cm}^{2}$ culture flasks. Morphological examination confirmed a homogeneous population of stellate-shaped cells typical of mesangial cells in culture. For the current experiments, mesangial cells between the twelfth and twenty-fifth passage were used.

DNA synthesis and cell proliferation experiments. Cellular incorporation of $\left[{ }^{3} \mathrm{H}\right]$ thymidine was used to assess DNA replication. Mesangial cells were seeded in 96-well culture plates at a density of $2 \times 10^{4}$ cells per well. At confluency, the cells were synchronized to the quiescent state by incubation in serum-free RPMI 1640 containing $5 \mathrm{ml}$ insulintransferrin-selenite per liter. After $48 \mathrm{~h}$, cells were exposed to RPMI 1640 containing $10 \%$ fetal bovine serum to stimulate mitogenesis. Some cells were also exposed to either lovastatin $(1-20 \mu \mathrm{M})$ alone or to lovastatin plus one of the following: mevalonate $(100 \mu \mathrm{M})$, isopentenyl adenine (IPA, 5 or $50 \mu \mathrm{M})$, farnesol $(5 \mu \mathrm{M})$, or LDL $(100 \mu \mathrm{g} / \mathrm{ml})$. Tritiated thymidine $\left(1 \mu \mathrm{Ci} /\right.$ well) was added to all wells, and total ${ }^{3} \mathrm{H}$ incorporation was measured over a $42-\mathrm{h}$ period. Cells were harvested using a PHD cell harvester (Cambridge Technology, Inc., Cambridge, MA), collected on glass fiber filters, and placed in $2 \mathrm{ml}$ scintillation cocktail for determination of total radioactivity.

For determination of cell proliferation, mesangial cells were seeded in 24-well culture plates at a density of $5 \times 10^{3}$ cells per well. At $\sim 60 \%$ confluency, cells were synchronized to quiescence as described above. After $48 \mathrm{~h}$, the cells were exposed to RPMI 1640 containing $10 \%$ fetal bovine serum in the absence or presence of the agents listed above. The media was replaced after $72 \mathrm{~h}$, and after an additional $48 \mathrm{~h}$, cell numbers were determined.

Lipoprotein fractionation. The density of fresh human plasma was adjusted to $d_{1.019}$ by the addition of $\mathrm{KBr}$. The sample was centrifuged at $40,000 \mathrm{rpm}$ for $16 \mathrm{~h}$ at $4^{\circ} \mathrm{C}$ in an ultracentrifuge with a Ti 50.2 rotor (L875; Beckman Instruments, Inc., Fullerton, CA). The VLDL layer was removed, the density of the infranate plasma was adjusted to $d_{1.063}$ by the addition of $\mathrm{KBr}$, and the sample was centrifuged as above. The floating layer, representing the density fractions $d_{1.019}-d_{1.063}$, contained LDL. The LDL layer was removed and dialyzed at $4^{\circ} \mathrm{C}$ for $24 \mathrm{~h}$ against several changes of RPMI 1640. The protein content of LDL was determined using the Lowry method.

\section{Results}

In two separate experiments, exposure of quiescent mesangial cells to medium containing $10 \%$ fetal bovine serum caused an $\sim$ 14-fold increase in DNA synthesis as assessed by $\left[{ }^{3} \mathrm{H}\right]$ thymidine incorporation (Figs. 1 and 2 ). In both experiments, lovastatin caused a dose-dependent reduction in serumstimulated mesangial cell DNA synthesis (Figs. 1 and 2). At the highest lovastatin concentration $(20 \mu \mathrm{M}),\left[{ }^{3} \mathrm{H}\right]$ thymidine incorporation was reduced $>80 \%$. The inhibitory effect of lovastatin on DNA synthesis was completely prevented in the presence of exogenous mevalonate (Fig. 1). At each lovastatin concentration, mevalonate maintained $\left[{ }^{3} \mathrm{H}\right]$ thymidine incorporation at the control level observed in cells exposed only to serum.

Lovastatin inhibition of DNA synthesis was only partially restored in the presence of IPA, and then only at the lower lovastatin concentrations (Fig. 2). At a concentration of $1 \mu \mathrm{M}$, lovastatin alone reduced $\left[{ }^{3} \mathrm{H}\right]$ thymidine incorporation by $33 \%$. In the presence of $5 \mu \mathrm{M}$ IPA, the same lovastatin concentration caused a $15 \%$ reduction in thymidine incorporation. At higher

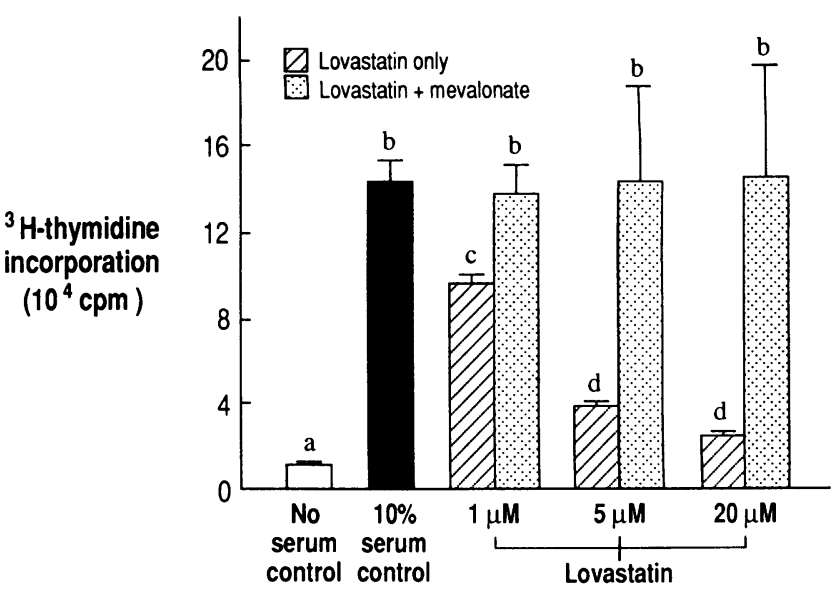

Figure 1. DNA synthesis $\left(42-\mathrm{h}\left[{ }^{3} \mathrm{H}\right]\right.$ thymidine incorporation) in confluent mesangial cells stimulated by $10 \%$ fetal bovine serum. Data represent mean $\pm \mathrm{SE}$ of quadruplicate samples (each sample was total $\mathrm{cpm}$ obtained from four wells of a 96-well culture plate). Mevalonate was used at a concentration of $100 \mu \mathrm{M}$. Different letters indicate $P$ $<0.05$.

lovastatin doses, IPA produced minimal or no restoration of DNA synthesis. Increasing the IPA concentration to $50 \mu \mathrm{M}$ did not cause any further effect of IPA on thymidine incorporation (data not shown). By contrast, the isoprenoid farnesol, at a concentration of $5 \mu \mathrm{M}$, completely or nearly completely prevented the lovastatin inhibition of mesangial cell DNA synthesis (Fig. 3).

Addition of LDL cholesterol to the culture medium did not prevent lovastatin inhibition of mesangial cell DNA synthesis (Fig. 4). Cells exposed to lovastatin plus $100 \mu \mathrm{g} / \mathrm{ml} \mathrm{LDL}$ showed dose-response inhibition of DNA synthesis comparable to that in cells in earlier experiments (Figs. 1 and 2) that were treated with lovastatin alone.

The results of the cell proliferation experiments paralleled the results of $\left[{ }^{3} \mathrm{H}\right]$ thymidine incorporation. Exposure of quies-

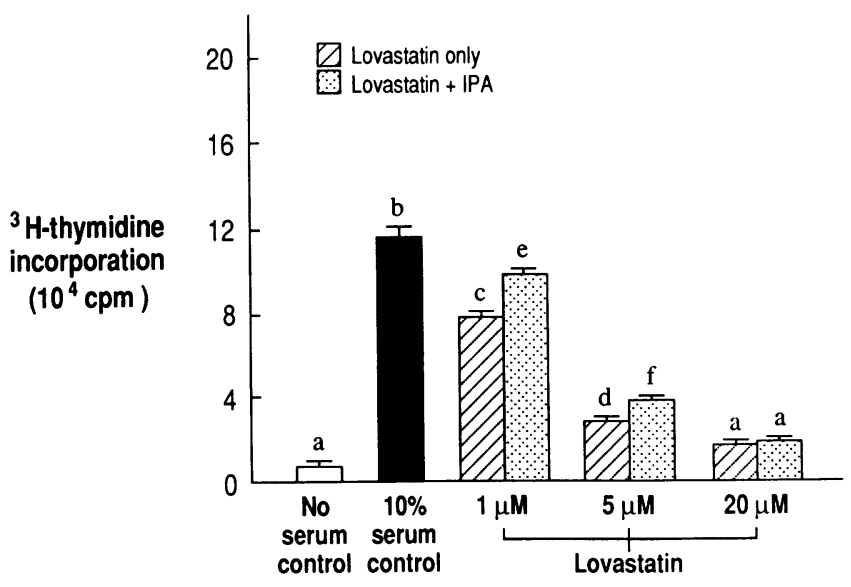

Figure 2. DNA synthesis $\left(42-\mathrm{h}\left[{ }^{3} \mathrm{H}\right]\right.$ thymidine incorporation) in confluent mesangial cells stimulated by $10 \%$ fetal bovine serum. Data represent mean $\pm \mathrm{SE}$ of quadruplicate samples (each sample was total cpm obtained from four wells of a 96-well culture plate). IPA was used at a concentration of $5 \mu \mathrm{M}$. Different letters indicate $P<0.05$. 


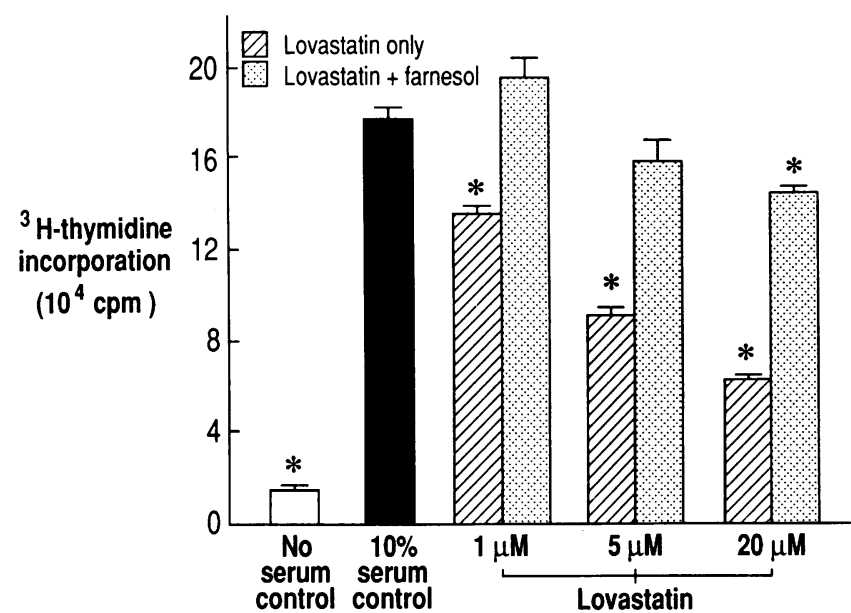

Figure 3. DNA synthesis $\left(42-\mathrm{h}\left[{ }^{3} \mathrm{H}\right]\right.$ thymidine incorporation) in confluent mesangial cells stimulated by $10 \%$ fetal bovine serum. Data represent mean $\pm \mathrm{SE}$ of quadruplicate samples (each sample was total cpm obtained from four wells of a 96-well culture plate). Farnesol was used at a concentration of $5 \mu \mathrm{M} .{ }^{*} P<0.05$ vs. $10 \%$ serum control.

cent cells to $10 \%$ fetal bovine serum caused a $>40$-fold increase in cell number over the 5-d study period (Fig. 5). Lovastatin (1 $\mu \mathrm{M}$ ) reduced cell proliferation by $\sim 90 \%$, and this effect was largely prevented by exogenous mevalonate. IPA, on the other hand, had no significant action in preventing lovastatin inhibition of cell proliferation.

\section{Discussion}

Previous in vitro work has demonstrated the necessity of mevalonate for growth and proliferation of a number of cell types, including human fibroblasts and lymphocytes, baby hamster kidney cells, vascular smooth muscle cells, and Swiss 3T3 cells (1-8). The present results indicate that glomerular mesangial cells also require mevalonate for DNA synthesis and cell division. ${ }^{2}$ Lovastatin, a competitive inhibitor of mevalonate synthesis from HMG-CoA, caused a dose-dependent reduction in mesangial cell DNA replication. Moreover, at a concentration of $1 \mu \mathrm{M}$, lovastatin reduced mesangial cell proliferation by $\sim 90 \%$. These effects of lovastatin were overcome by simultaneous exposure of mesangial cells to exogenous mevalonate.

Mevalonate metabolism produces a series of isoprenoid intermediates which, in turn, are converted into particular end products necessary for cell growth and proliferation $(5,8)$. One critical end product of mevalonate metabolism is cholesterol which, in proliferating cells, is required for cell membrane for-

2. The present experiments describe the effects of lovastatin on proliferation of glomerular mesangial cells isolated from obese Zucker rats. We have recently found that lovastatin also inhibits DNA synthesis in glomerular mesangial cells from lean Zucker rats as well as in cultured human mesangial cells. Thus, the effects of lovastatin to inhibit DNA synthesis and proliferation in glomerular mesangial cells are not unique to mesangial cells obtained from obese Zucker rats.

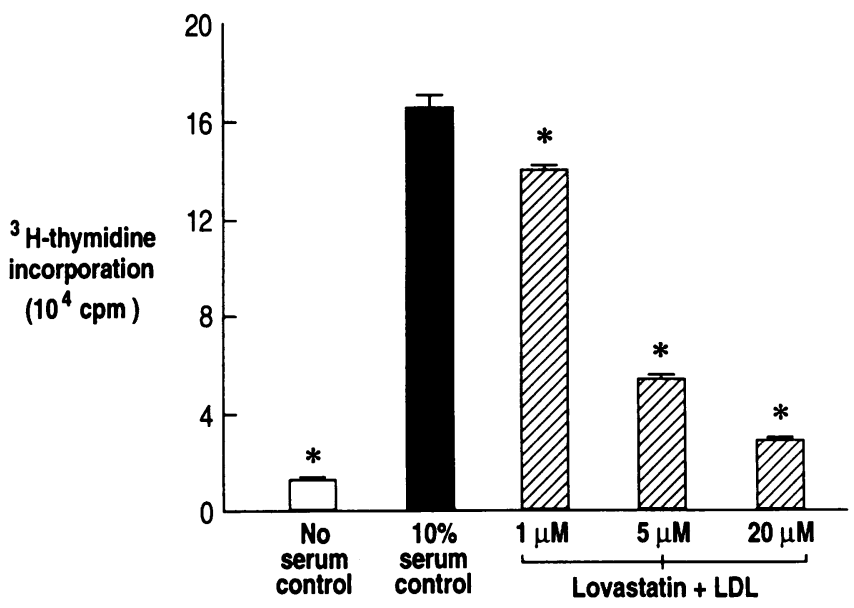

Figure 4. DNA synthesis (42-h $\left[{ }^{3} \mathrm{H}\right]$ thymidine incorporation) in confluent mesangial cells stimulated by $10 \%$ fetal bovine serum. Data represent mean $\pm \mathrm{SE}$ of quadruplicate samples (each sample was total cpm obtained from four wells of a 96-well culture plate). As in previous experiments, lovastatin was used at concentrations of 1,5 , and $20 \mu \mathrm{M}$. LDL was present at a concentration of $100 \mu \mathrm{g} / \mathrm{ml} .{ }^{*} P<0.05$ vs. $10 \%$ serum control.

mation. The cholesterol requirement for cell proliferation appears to be restricted to the early $G_{1}$ phase of the cell cycle (3). It might be argued, then, that inhibition of cholesterol synthesis was a possible mechanism by which lovastatin reduced mesangial cell proliferation. It is unlikely, however, that inhibition of cholesterol synthesis explains the actions of lovastatin on mesangial cell DNA synthesis and proliferation. Mesangial cells were stimulated to proliferate by exposure to medium containing $10 \%$ fetal bovine serum. The serum provided an exogenous source of cholesterol for cell membrane synthesis. The cholesterol concentration of the serum-supplemented medium was calculated to be $\sim 40 \mu \mathrm{g} / \mathrm{ml}$, a level previously described as sufficient for proliferation of cultured cells (1). Moreover, in

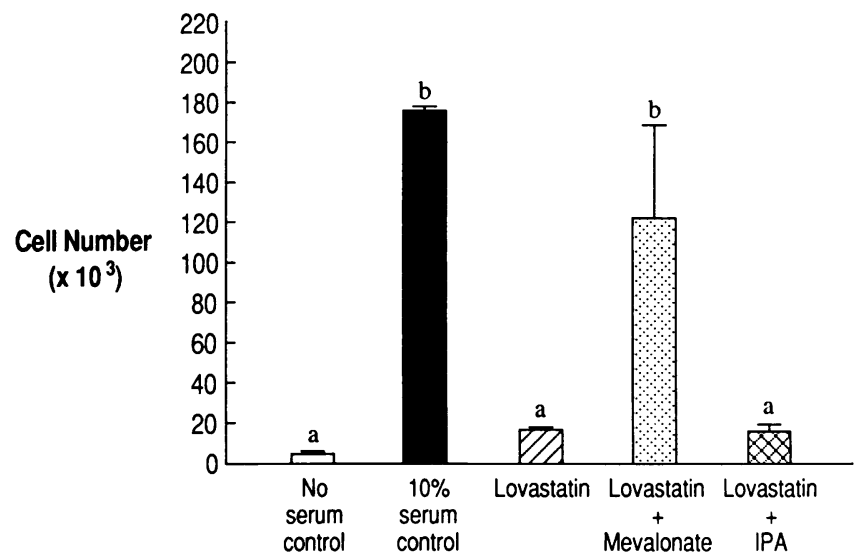

Figure 5. Total numbers of mesangial cells stimulated to proliferate by $10 \%$ fetal bovine serum over a $5-d$ period. Stimulation was initiated at $\sim 60 \%$ confluency. Data represent mean \pm SE of triplicate wells of a 24-well culture plate. Concentrations of agents used: lovastatin $(1 \mu \mathrm{M})$; mevalonate $(100 \mu \mathrm{M})$; isopentenyl adenine $(5 \mu \mathrm{M})$. Different letters indicate $P<0.05$. 
some experiments, additional LDL cholesterol was added to lovastatin-treated mesangial cells. The added cholesterol did not prevent the inhibitory effects of lovastatin on mesangial cell DNA synthesis. These results were similar to those in other cell types in which exogenous cholesterol was ineffective in preventing the inhibitory effects of HMG-CoA reductase inhibitors on cell proliferation $(1,4)$. Importantly, also, experiments in other cell types have demonstrated that cholesterol does not directly affect DNA replication $(2,4)$. Thus, inhibition of DNA synthesis in lovastatin-treated mesangial cells was probably not a direct effect of reduced cholesterol availability, but likely resulted from inhibition of production of one or more isoprenoid intermediates of mevalonate metabolism.

IPA is an isoprenoid end product that may be important in the regulation of cell proliferation. Some experimental data have suggested that IPA may be a requirement for cells to enter the S-phase of the cell cycle. In baby hamster kidney cells, IPA largely restored DNA synthesis in compactin-treated cells, but only when both compactin and IPA were added in the late $G_{1}$ phase of the cell cycle (3). When baby hamster kidney cells in early $G_{1}$ were exposed to both compactin and IPA, IPA did not stimulate DNA synthesis (3). Our results in mesangial cells were similar to these latter findings. IPA was largely ineffective in restoring serum-stimulated DNA synthesis when added to growth-arrested, lovastatin-blocked mesangial cells. Thus, it appears that cells must reach the $G_{1}-S$ interphase of the cell cycle before IPA might replace mevalonate to stimulate DNA synthesis (3). These results further suggest that other isoprenoid metabolites of mevalonate are required to initiate the cell cycle and that entry into the cell cycle can be prevented by lovastatin inhibition of those isoprenoids.

One isoprenoid that may be critical for initiation of cell proliferation is farnesol. Some intracellular proteins covalently bond farnesol, including ras proteins and other ras-related, low molecular mass, GTP-binding proteins (8, 16-19). Farnesylated $\mathrm{p} 21^{\text {ras }}$ proteins attach to the inner surface of the cell membrane, and may serve as signaling mechanisms for growth factors $(8,16,17,20-22)$. In this study, therefore, it is possible that lovastatin inhibited mesangial cell proliferation, at least in part, by blocking the production of farnesol and farnesylated proteins. This, in turn, may have prevented the actions of serum growth factors to stimulate entry of the growth-arrested mesangial cells into the cell cycle. Our results with exogenous farnesol support this possibility. Mesangial cells appeared to be capable of uptake and utilization of farnesol added to the culture medium. Importantly, farnesol prevented the inhibitory action of lovastatin on mesangial cell proliferation.

We have previously shown in several experimental models of progressive glomerular disease that chronic daily administration of lovastatin reduced albuminuria and the extent of structural injury (9-11). Because lovastatin also reduced circulating lipid levels in those models, it was proposed that lipid abnormalities, e.g., hypercholesterolemia, can both initiate glomerular injury and participate in the progression of glomerular disease (9-11). The results of the present study suggest that lovastatin may also have acted to reduce glomerular injury, in part, by inhibiting mesangial cell proliferation.

It is difficult to predict how the in vitro concentrations of lovastatin used in the present experiments compare with plasma levels of lovastatin achieved in our previous in vivo studies (9-11). There is no information regarding the pharma- cokinetics of lovastatin administered to rats, although there are some limited pharmacokinetic data regarding lovastatin disposition in normal men (23). In subjects given a 40-mg dose $(\sim 0.5 \mathrm{mg} / \mathrm{kg}$ body $\mathrm{wt})$, the peak plasma concentration of "active" HMG-CoA reductase inhibitors was $\sim 30 \mathrm{ng} / \mathrm{ml}$. This would be equivalent to a lovastatin concentration of $\sim 0.07$ $\mu \mathrm{M}$. If the pharmacokinetic behavior of lovastatin were similar in rats and humans, then for a lovastatin dose of $4 \mathrm{mg} / \mathrm{kg}$ in rats (9-11), the peak plasma concentration of lovastatin would be $\sim 0.5 \mu \mathrm{M}$. In the present experiments, lovastatin at a concentration of $1 \mu \mathrm{M}$ inhibited mesangial cell proliferation by nearly $90 \%$ over a $5-d$ period. Thus, the in vitro lovastatin concentrations used in the present study may be similar to, albeit somewhat higher than, those that occur in vivo in rats administered the drug at a dose $(4 \mathrm{mg} / \mathrm{kg}$ body $\mathrm{wt})$ which significantly reduces glomerular structural injury (9-11).

In conclusion, the present results not only demonstrate the importance of mevalonate metabolism for mesangial cell proliferation, but also offer an important additional mechanism by which lovastatin may reduce glomerular injury. Future experiments will be important in rats with glomerular disease that are treated with lovastatin and fed high cholesterol chow to maintain hypercholesterolemia. Such experiments will be necessary to define whether lovastatin can reduce experimental glomerular injury in the absence of a reduction in circulating cholesterol levels.

\section{Acknowledgments}

The authors thank Joel Phillips and Frank Daniels for expert technical assistance, and Ellen Davis for assistance in the manuscript preparation.

This work was supported, in part, by grants from Merck Sharp and Dohme and the Extramural Grant Program of Baxter Healthcare Corporation.

\section{References}

1. Quesney-Huneeus, V., M. H. Wiley, and M. D. Siperstein. 1979. Essential role for mevalonate synthesis in DNA replication. Proc. Natl. Acad. Sci. USA. 76:5056-5060.

2. Habenicht, A. J. R., J. A. Glomset, and R. Ross. 1980. Relation of cholesterol and mevalonic acid to the cell cycle in smooth muscle and Swiss 3T3 cells stimulated to divide by platelet-derived growth factor. J. Biol. Chem. 255:51345140 .

3. Quesney-Huneeus, V., H. A. Galick, M. D. Siperstein, S. K. Erickson, T. A. Spencer, and J. A. Nelson. 1983. The dual role of mevalonate in the cell cycle. $J$. Biol. Chem. 258:378-385.

4. Fairbanks, K. P., L. D. Witte, and D. S. Goodman. 1984. Relationship between mevalonate and mitogenesis in human fibroblasts stimulated with platelet-derived growth factor. J. Biol. Chem. 259:1546-1551.

5. Siperstein, M. D. 1984. Role of cholesterogenesis and isoprenoid synthesis in DNA replication and cell growth. J. Lipid Res. 25:1462-1468.

6. Maltese, W. A., and K. M. Sheridan. 1985. Differentiation of neuroblastoma cells induced by an inhibitor of mevalonate synthesis: relation of neurite outgrowth and acetylcholinesterase activity to changes in cell proliferation and blocked isoprenoid synthesis. J. Cell. Physiol. 125:540-588.

7. Cutts, J. L., T. J. Scallen, J. Watson, and A. D. Bankhurst. 1989. Role of mevalonic acid in the regulation of natural killer cell cytotoxicity. J. Cell. Physiol. 139:550-557.

8. Goldstein, J. L., and M. S. Brown. 1990. Regulation of the mevalonate pathway. Nature (Lond.). 343:425-430.

9. Kasiske, B. L., M. P. O'Donnell, M. P. Cleary, and W. F. Keane. 1988. Treatment of hyperlipidemia reduces glomerular injury in obese Zucker rats. Kidney Int. 33:667-672.

10. Kasiske, B. L., M. P. O’Donnell, W. J. Garvis, and W. F. Keane. 1988. Pharmacologic treatment of hyperlipidemia reduces glomerular injury in rat 5/6 nephrectomy model of chronic renal failure. Circ. Res. 62:367-374. 
11. O'Donnell, M. P., B. L. Kasiske, P. G. Schmitz, S. A. Katz, and W. F Keane. 1992. Lovastatin but not enalapril reduces glomerular injury in Dahl salt-sensitive rats. Hypertension (Dallas). 20:651-658.

12. Kita, T., M. S. Brown, and J. L. Goldstein. 1980. Feedback regulation of 3-hydroxy-3-methylglutaryl coenzyme A reductase in livers of mice treated with mevinolin, a competitive inhibitor of the reductase. J. Clin. Invest. 66:10941100.

13. Harper, P. A., J. M. Robinson, R. L. Hoover, T. C. Wright, and M. J. Karnovsky. 1984. Improved methods for culturing rat glomerular cells. Kidney Int. 26:875-880.

14. Mené, P., and M. J. Dunn. 1986. Contractile effects of TxA $A_{2}$ and endoperoxide analogues on cultured rat glomerular mesangial cells. Am. J. Physiol. 251:F1029-F1035.

15. Schlondorff, D., S. Decandido, and J. S. Satriano. 1987. Angiotensin II stimulates phospholipases $\mathrm{C}$ and $\mathrm{A}_{2}$ in cultured rat mesangial cells. Am. J. Physiol. 253:C113-C120.

16. Casey, P. J., P. A. Solski, C. J. Der, and J. E. Buss. 1989. p21 ras is modified by a farnesyl isoprenoid. Proc. Natl. Acad. Sci. USA. 86:8323-8327.
17. Hancock, J. F., A. I. Magee, J. E. Childs, and C. J. Marshall. 1989. All ras proteins are polyisoprenylated but only some are palmitoylated. Cell. 57:11671177

18. Jackson, J. H., C. G. Cochrane, J. R. Bourne, P. A. Solski, J. E. Buss, and C. J. Der. 1990. Farnesol modification of Kirsten-ras exon 4B protein is essential for transformation. Proc. Natl. Acad. Sci. USA. 87:3042-3046.

19. Maltese, W. A., K. M. Sheridan, E. M. Repko, and R. A. Erdman. 1990. Posttranslational modification of low molecular mass GTP-binding proteins by isoprenoid. J. Biol. Chem. 265:2148-2155.

20. Molloy, C. J., D. P. Bottaro, T. P. Fleming, M. S. Marshall, J. B. Gibbs, and S. A. Aaronson. 1989. PDGF induction of tyrosine phosphorylation of GTPase activating protein. Nature (Lond.). 342:711-714.

21. Santos, E., and A. R. Nebreda. 1989. Structural and functional properties of ras proteins. FASEB (Fed. Am. Soc. Exp. Biol.) J. 3:2151-2163.

22. Mendola, C. E., and J. M. Backer. 1990. Lovastatin blocks N-ras oncogene-induced neuronal differentiation. Cell Growth \& Differ. 1:499-502.

23. Pan, H. Y., A. R. DeVault, D. Wang-Iverson, E. Ivashkir, B. N. Swanson, and A. A. Sugerman. 1990. Comparative pharmacokinetics and pharmacodynamics of pravastatin and lovastatin. J. Clin. Pharmacol. 30:1128-1135. 